\title{
De madera y hormigón: hábitat residencial y habitar de migrantes latinoamericanos en la ciudad de Santiago
} On Wood and concrete: residential habitat and inhabit of Latin American migrants in
the city of Santiago

\section{Cristóbal Sebastián Palma Rojas \\ Universidad Alberto Hurtado, Chile}

RESUMEN En base a dos experiencias etnográficas, una en un campamento (asentamiento informal) ubicado en el extremo norte del Gran Santiago y otra, aún en curso, en zonas de verticalización residencial en el centro de la comuna de Santiago, el presente artículo discute sobre la influencia de las materialidades y espacialidades de la vivienda en la configuración del habitar de migrantes latinoamericanos en la Región Metropolitana. Se concluye que el hábitat en campamentos, cuya espacialidad y materialidad son de orden flexible y en permanente construcción, permite formas de apropiación espacial, de tipo simbólico y material, conforme se procede a la edificación y mejora de la vivienda, mientras que el hábitat en zonas de verticalización residencial cuya materialidad es rígida y se encuentra pre-definida, restringe de manera sustantiva las posibilidades de apropiación espacial a nivel material. Aun así, en la intimidad de la vivienda y a nivel simbólico y afectivo se producen formas de domesticación del espacio residencial que resultan modeladas por sus usuarios migrantes.

PALABRAS CLAVE Migración latinoamericana; campamentos; verticalización residencial; vivienda.

ABSTRACT Based on two ethnographic experiences, one in a shantytown located at the periphery of Greater Santiago and another, still ongoing, in verticalization areas in the center of the city of Santiago, this article discusses the influence of materialities and housing spatialities in the configuration of inhabit 
of Latin American migrant living in the Metropolitan Region. It concludes that the habitat in the shantytown, whose spatiality and materiality are of a plastic order and in permanent construction, allows forms of spatial appropriation, of symbolic and material order, as the building and improvement of the housing proceed, while the habitat in residential verticalization zones whose materiality is rigid and preset, restricts the possibilities of spatial appropriation at the material level. However, in the intimacy of the house and at the symbolic and affective dimension there are forms of domestication of the residential space which are modeled by its migrant users.

KEYWORDS Latin American migration; shantytowns; residential verticalization; housing.

\section{Introducción}

Chile se ha consolidado durante los últimos años como un país de destino para migrantes de origen latinoamericano y caribeño. De acuerdo al INE (2019) en la actualidad más de 1.251.225 personas que residen en el país son de origen extranjero, representando al 6,6\% de la población total del país. Asimismo, el crecimiento sostenido de la migración en Chile ha llevado a que actualmente $7 \%$ de los más de 7 millones de residentes de la Región Metropolitana de Santiago sean extranjeros. De ellos, de acuerdo al Censo de 2017 destacan principalmente personas provenientes Venezuela, Perú, Colombia y Haití.

De entre los diversos desafíos que la migración latinoamericana presenta para la sociedad chilena un tema recurrente, abordado en ensayos, investigaciones y artículos periodísticos, ha sido su inserción habitacional. Algunas investigaciones en el ámbito de las ciencias sociales han destacado que la situación habitacional de los migrantes latinoamericanos en Santiago y otras grandes ciudades del país, se encuentra atravesada por una serie de prácticas abusivas tales como la proliferación de un mercado informal de arriendo y subarriendo, la existencia de espacios inadecuados para la habitabilidad, entre otras formas de discriminación asociadas con color de piel o el país de procedencia (Contreras, Ala-Louko y Labbé, 2015; Curahua, 2013 ; López, Flores y Orozco, 2018).

Más allá de estas constataciones, otro grupo de investigaciones han venido refiriendo los efectos transformadores de la migración latinoamericana sobre el espacio urbano. Con diferentes matices, estas investigaciones han señalado que la presencia de migrantes latinoamericanos en la ciudad produce modificaciones de orden material y simbólico sobre ciertas áreas, actualizando, superponiendo o yuxtaponiendo ordenes espaciales que se engarzan en actividades comerciales, festivas o residencia- 
les y otorgando nuevos usos y significados al espacio público y residencial (Imilán, 2014; Márquez, 2014; Stefoni, 2015).

Así, investigaciones como las de Garcés (2012), Imilán (2014), Stefoni (2015), entre otros, han explorado en cuestiones como el comercio migrante callejero, la instalación de restaurantes étnicos o el uso del espacio público, y cómo estas prácticas permiten anclajes específicos, creación de vínculos, afirmación y visibilidad de sus expresiones culturales en que tensionan las espacialidades tradicionales, dotando de apropiaciones, usos y afectos a los inmigrantes en la ciudad.

Sin embargo, han sido pocas las investigaciones que se han abocado a estudiar estas transformaciones teniendo como eje específico el hábitat residencial. Aun así, autoras como Margarit y Bijit (2014) han destacado las potencialidades territoriales, laborales y sociales que otorgan los lugares que los inmigrantes escogen para vivir, no obstante, la influencia específica del hábitat en la configuración del habitar migrante no ha sido aun suficientemente explorada.

En este último plano, el presente artículo se interroga por la influencia del hábitat, es decir, de la integración de los hechos físicos y materiales del espacio en la producción del habitar, esto es, la capacidad de individuos y grupos para imprimir un sello propio sobre el espacio, de dos áreas residenciales en las que viven actualmente migrantes de origen latinoamericano: un campamento (o urbanización informal) ubicado en el extremo norte del AMS (Área Metropolitana de Santiago) y una zona de verticalización residencial ubicada en el centro de la comuna de Santiago. La elección de estas áreas residenciales no resulta antojadiza, más bien permite contrastar y conjugar dos formas emergentes del hábitat migrante en la ciudad de Santiago. Una central y una periférica, una formal y otra informal, una producida y otra autoproducida, una de madera y otra de hormigón. Dando cuenta de cómo, en ambos casos, los espacios habitados se convierten en lugares cargados de sentido vital para sus usuarios. Se ha dejado fuera del presente artículo otra de las formas frecuentes de hábitat migrante en la ciudad de Santiago como es el hábitat en conventillos, de carácter cuasi-formal y de adobe, principalmente porque ha sido materia de numerosos estudios, sobre todo referentes a la migración peruana y configura un tipo de hábitat que se podría denominar "consolidado", por su recurrencia en el tiempo (ver, por ejemplo: Contreras et al., 2015; Luque, 2004; Margarit y Bijit, 2014).

Con todo, una primera parte del artículo está dedicada a definir conceptualmente las nociones de hábitat y habitar. Posteriormente, se presentan ambos casos de estudio y la metodología con que fueron abordados. Finalmente, se establecen particularidades de cada forma de hábitat residencial en relación a las posibilidades de apropiación espacial y algunos elementos comunes a ambas formas de habitar. Por último, señalar que este artículo forma parte de una agenda investigativa mayor de exploraciones sobre hábitat, paisaje y territorios migrantes aún en curso, que eventualmente podría complejizar o reelaborar algunos de sus hallazgos o marcos interpretativos. 


\section{Hábitat residencial y habitar}

Hábitat y habitar, son dos conceptos cardinales en el ámbito de los estudios urbanos que han sido abordados por una serie de disciplinas de las ciencias sociales y las humanidades, tales como la geografía, la historia, la antropología y la sociología. Tradicionalmente se ha comprendido al hábitat como aquellos sitios geográficos donde se despliegan las actividades vitales de los individuos (Camacho, 2001). Más en específico, el hábitat es concebido como el ordenamiento de los hechos físicos-espaciales resultante de procesos sociales, económicos, históricos, culturales y/o geográficos, en diferentes escalas (país, ciudad, barrio, vivienda) (Giglia, 2013).

Más acá, el hábitat residencial se entiende como el ordenamiento de un ambiente físico-espacial resultante del asentamiento de un conjunto de personas en un área específica de la ciudad con fines residenciales (De la Puente, Muñoz y Torres, 1989). Así, cada forma que adquiere el hábitat residencial puede entenderse a partir de las normas y regularidades de uso que expresan los contenidos de los lazos sociales y el modo de estar juntos en ciertos espacios y tiempos concretos (Giglia, 2013).

Una de las formas recurrentes de caracterizar el hábitat residencial ha sido a través de su división en hábitat formal e informal, diferenciada por la situación de tenencia con respecto a la tierra y la vivienda o los códigos constructivos que predominan en determinadas condiciones urbano-ambientales. Así, la noción de hábitat formal, remite a la idea de lugares de asentamiento de grupos humanos que se encuentran jurídicamente reglamentados, y que cuentan con códigos constructivos diseñados y planificados por instituciones estatales o bien por el mercado inmobiliario, cumpliendo con los requerimientos específicos de planificación establecidos por el Estado o el ordenamiento jurídico (Clichevsky, 200o; Di Virgilio, Arqueros y Guevara, 2010). De otro lado, el hábitat informal ha sido caracterizado esencialmente a partir de la carencia de marcos jurídicos y mediación de instituciones estatales. A menudo, su planificación suele no respetar ciertos criterios urbanísticos, relacionado con el tamaño de los lotes, la apertura de calles o la prevención de riesgos ambientales en la edificación de barrios y viviendas. Más allá de sus ausencias, también se han puesto en valor la existencia de formas de planificación "otras", presentes en el hábitat informal, que surgen desde necesidades propias de sus usuarios, generalmente habitantes pobres de las ciudades, las cuales incluso desafían, velada o intencionadamente, el orden espacial del hábitat formal (Negro, 2016; Skewes, 2005).

Indisociable de la noción de hábitat, un concepto que se ha asociado de manera recurrente a la construcción de asentamientos humanos es la noción de habitar. Con ella se remite al proceso mediante el cual los individuos o grupos humanos se apropian del hábitat construido por otros (en el caso del hábitat formal) o por ellos mismos (en el caso del hábitat informal o autoproducido). 
Siguiendo a Lefebvre:

"[...]habitar, para el individuo o para el grupo es apropiarse de algo. Apropiarse no es tener propiedad sino hacer su obra, moldearla, formarla, ponerle el sello propio. Esto es cierto tanto para pequeños grupos, por ejemplo, la familia, como para grandes grupos sociales [...] habitar es apropiarse de un espacio: es también hacer frente a los constreñimientos, es decir, es el lugar del conflicto, a menudo agudo entre los constreñimientos y las fuerzas de apropiación" (Lefebrve, 1975, p. 210).

Visto así, el habitar podría entenderse como una práctica humana creativa mediante la cual los usuarios convierten el hábitat (en cuanto orden físico-espacial que abarca desde la vivienda hasta el barrio) en lugar que integra sus prácticas específicas, su afectividad, imaginación y sello. Siguiendo a Giglia (2013) y a Álvarez y Blanco (2013) el habitar, o la domesticación del espacio social, sería el resultado de un proceso de reiteración de prácticas y acumulación de rutinas en el ámbito de lo cotidiano que permite el devenir de los espacios en lugares cargados de sentido vital. Si bien el habitar remite a una serie de formas de ser-estar en el mundo que exceden lo "domestico" o "vecinal" y se vinculan también con las movilidades, el caso de estudio presentado se restringirá a esta primera dimensión.

Asimismo, la noción de hábitat residencial a menudo es comprendida y utilizada también atendiendo a la integración de ambas dimensiones, la del hábitat y el habitar, tal como plantean Tapia, Lang y Larenas (2009) el hábitat residencial es entendido como:

“aquel espacio intervenido directa y activamente por los habitantes [...] más que circunscribirse a la vivienda misma, su carácter residencial se manifiesta en la posibilidad de ampliar territorialmente su ámbito de interacciones significativas con el espacio habitado y con otros habitantes, nutriendo así la conformación del ámbito de lo propio" (Tapia et al., 2009, p. 51).

Sin embargo, para establecer una diferencia en términos analíticos, se utilizarán ambas nociones de modo separado, para establecer el ordenamiento material, por un lado, y los significados asociados a dicho ordenamiento, por el otro.

\section{Metodología}

Los resultados que se exponen a continuación son el producto de dos investigaciones cualitativas y etnográficas llevadas a cabo en zonas residenciales que concentran alta cantidad de población migrante. En ambos casos, se elaboraron pautas de entrevista abierta o etnográfica con temas relacionados a la experiencia residencial, además de pautas de observación participante (Guber, 2001) dedicadas a registrar actores, prácticas y materialidades presentes en el espacio. 
La primera de ellas fue llevada a cabo en el campamento Nueva Vida de la comuna de Colina. Un asentamiento informal conformado en 2016, por familias de origen chileno y extranjero. De entre los extranjeros destacan personas provenientes principalmente de República Dominicana y Haití, aunque también habitan en el campamento migrantes provenientes de Colombia, Perú y Bolivia. La investigación fue llevada a cabo entre los meses de junio de 2017 y abril de 2018, y tenía por objetivo indagar en las formas de habitar de migrantes latinoamericanos en áreas urbanas informales y su relación con la construcción de ciudadanía urbana. En esta investigación se realizaron más de 30 entrevistas en profundidad, sumado a una serie de jornadas de observación participante, sistematizadas mediante la construcción de un cuaderno de campo.

El segundo caso presentado, aún en curso, se realizó sobre el barrio Santa Isabel, en la comuna de Santiago. Esta área se caracteriza por concentrar más de un $78 \%$ de edificaciones en altura y por la alta presencia de migrantes latinoamericanos, principalmente de origen venezolano, peruano y colombiano (ATISBA, 2018). La investigación comenzó en marzo de 2019 y tiene por objetivo indagar en las formas de apropiación espacial de migrantes latinoamericanos en áreas de verticalización residencial. Hasta el momento se han realizado 5 entrevistas en profundidad sumado a una serie de jornadas de observación participante, sistematizadas mediante la construcción de un cuaderno de campo.

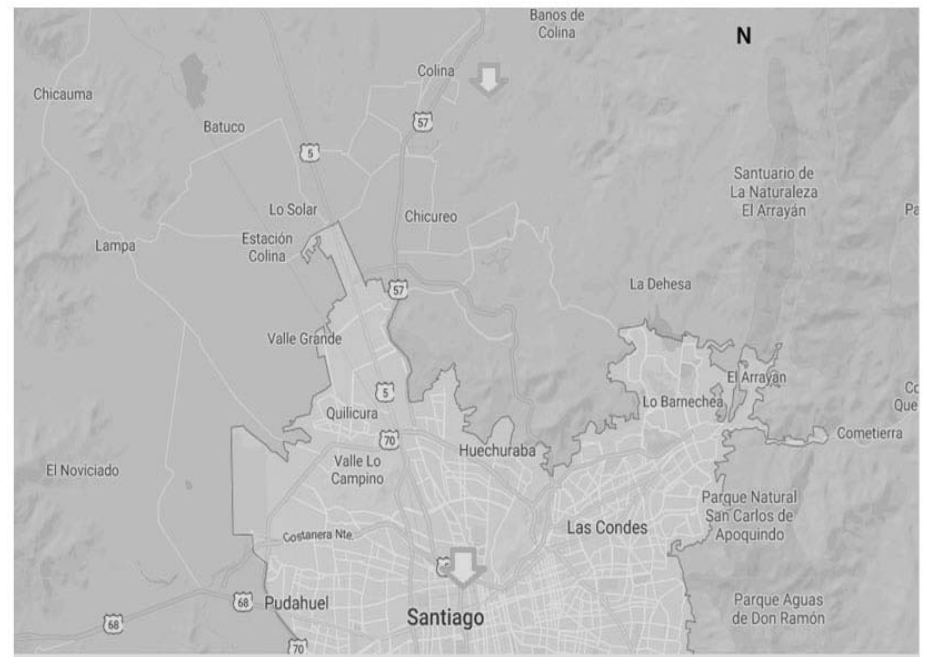

Figura 1: Localización de áreas donde se desarrolla la investigación Fuente: Google Maps, modificado por el autor. 
En ambos casos se utilizan series fotográficas tomadas en el marco de la investigación. Siguiendo los postulados de Álvarez y Blanco (2013) se consideran las imágenes como herramientas en diálogo con la escritura, pero de carácter autónomo. Esto quiere decir que las imágenes no buscan necesariamente ilustrar aquello que (no) dice el texto, sino más bien, generar otro tipo de sensaciones, percepciones y afectos de orden estético y artístico, igualmente significativas en relación al tema que se busca tratar.

Finalmente, cabe señalar que todos los nombres de personas que aparecen en los resultados son seudónimos utilizados para preservar el anonimato de los participantes.

\section{El campamento: (auto)construcción permanente y "vivir bien"}

Nueva Vida fue formado en 2016 cuando una docena de chilenos y extranjeros ocuparon un predio privado de aproximadamente una hectárea en las inmediaciones del Centro Penitenciario Colina II y el cementerio municipal a escasas cuadras del centro de la comuna de Colina. La información proporcionada por una serie de residentes del sector tiende a coincidir en señalar que fueron los primeros habitantes chilenos quienes comenzaron con el trazado de calles y el loteo de los sitios. Al inicio, cada sitio fue marcado con un número, muchos de los cuales hoy sirven para identificar cada vivienda.

El aumento de migrantes latinoamericanos en la comuna se debe a las importantes transformaciones inmobiliarias que ha sufrido Colina, pasando de ser un distrito principalmente rural, a incorporarse a la "extra periferia" de Santiago. Sobre todo, a partir de la construcción de viviendas de lujo para las clases más acomodadas de la región en sectores como Chicureo (Jirón y Mansilla, 2014). Ello ha redundado en el desarrollo de actividades laborales asociadas al servicio doméstico y la construcción, cuestión que resulta clave para entender la presencia de migrantes en el sector, ya que, en efecto, los datos del Censo de 2017 muestran que de las 146.207 personas que residen en Colina, 2.627 son de origen extranjero, las que provienen principalmente de Haití (19,6\%) y República Dominicana (18,2\%).

El trazado de calles al interior del campamento sigue la forma de un plano ortogonal, con tres calles principales, denominadas "República", "Dominicana" y "Vista Hermosa” y cuatro pasajes interiores. Las dos primeras calles fueron nombradas así por sus residentes, en buena parte dominicanos y la última adquiere este nombre en relación a la calle contigua que linda con el campamento e inicia el trazado formal de la ciudad. Cada terreno es diferente en relación a su contiguo, en cuanto a cantidad de metros y forma. 
Una buena parte de los terrenos está delimitada por rejas de madera y alambre, pero también existen otros que dan directo hacia la calle. Asimismo, al interior de cada terreno puede haber una o más viviendas, muchas de las cuales se ubican en la parte posterior de la "vivienda principal". Esto depende en gran medida de la llegada de nuevas familias que mediante cesión o venta van ocupando nuevas áreas aun despobladas al interior del campamento. Si bien el campamento no presenta un diseño "laberintico" como el señalado por Skewes (2005) para los asentamientos informales del siglo pasado, si muestra cierta irregularidad al interior de cada lote, lo que hace difícil establecer de buenas a primeras la cantidad de viviendas que hay por terreno, tal como muestra el siguiente croquis.

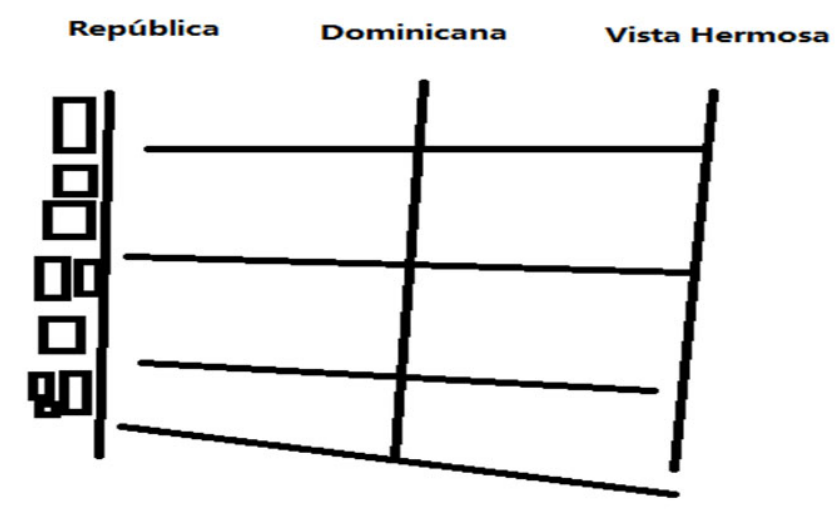

Figura 2: croquis campamento

Fuente: elaboración propia.

Para una buena parte de los extranjeros residentes en el campamento, el ingreso fue mediante compras informales. Según cuenta Alexis, migrante dominicano de unos 40 años, el debió desembolsar cerca de \$200.00o pesos por acceder a un terreno en $2017^{1}$. Sin embargo, más que un cobro irregular, este suele ser visto como una inversión y como garantía de seguridad para los residentes migrantes, ante situaciones de abuso frecuente en el mercado "formal" y cuasi formal de arriendos. Visto así, existe al interior del campamento un mercado de loteos y venta de terrenos que generalmente ha recaído en residentes chilenos. Sin embargo, con el tiempo se ha formado una directiva, compuesta por familias migrantes y chilenas, que ha intentado prohibir la venta de terrenos.

1. Cabe señalar que un terreno urbano en Santiago en áreas poco servidas sobrepasa ampliamente este monto, pudiendo costar desde 6 millones en adelante. 
Además de los cobros por terreno, los residentes del campamento debieron pagar inicialmente por la instalación de postes para alumbrado, máquinas para aplanar el terreno y cañerías para traer el agua desde un sector aledaño que cuenta con estos servicios regularizados. Sumado a ello, cada vez que se produce un corte de luz, un grupo de residentes del mismo campamento realiza cobros de $\$ 5000^{2}$ pesos para la reposición del servicio. El agua es cobrada mensualmente sobre una cuota fija establecida por la dueña del suministro, una mujer de una población aledaña que cobra $\$ 10.000$ a cada vivienda ${ }^{3}$. El consumo mensual de luz, en cambio, se obtiene de manera gratuita.

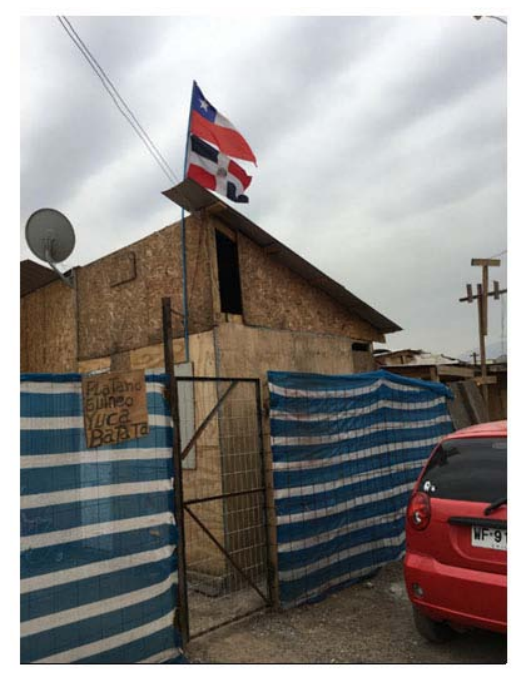

Figura 3: exterior de una casa en el campamento

Fuente: elaboración de Miguel Pérez.

Fuera de estos aspectos, acordados o impuestos, en materia de construcción de la vivienda existe bastante diversidad interna. Una mirada desatenta puede llevar a pensar que todas las viviendas son más o menos parecidas, puesto que comparten en términos estructurales algunos materiales de edificación, como son los tableros de madera aglomerada (OSB) y techos de zinc. Sin embargo, al observar con mayor detalle se puede ir dando cuenta de una serie de elementos en cuanto al acabado de las viviendas y ciertas diferencias estéticas, sobre todo en relación a las viviendas de chilenos y extranjeros.

2. Una cuenta mensual de luz en Santiago bordea los 12.000 pesos promedio.

3. Una cuenta mensual de agua en Santiago bordea los 8.000 pesos promedio. 
Mientras las familias chilenas tienden a construir de manera mucho más rudimentaria y poco sofisticada, las familias migrantes parecen mucho más dedicadas y comprometidas en la decoración de sus espacios residenciales, cuestión que se vuelve patente al comparar los materiales usados en puertas, pisos, rejas, etc. Por ejemplo, una buena parte de las viviendas de las familias migrantes ha acondicionado sus pisos con radier de cemento y cerámica, a diferencia de las de familias chilenas que tienen piso de tierra. Asimismo, la mayoría de las viviendas de migrantes cuentan con material de aislación como vulcanita en sus paredes.

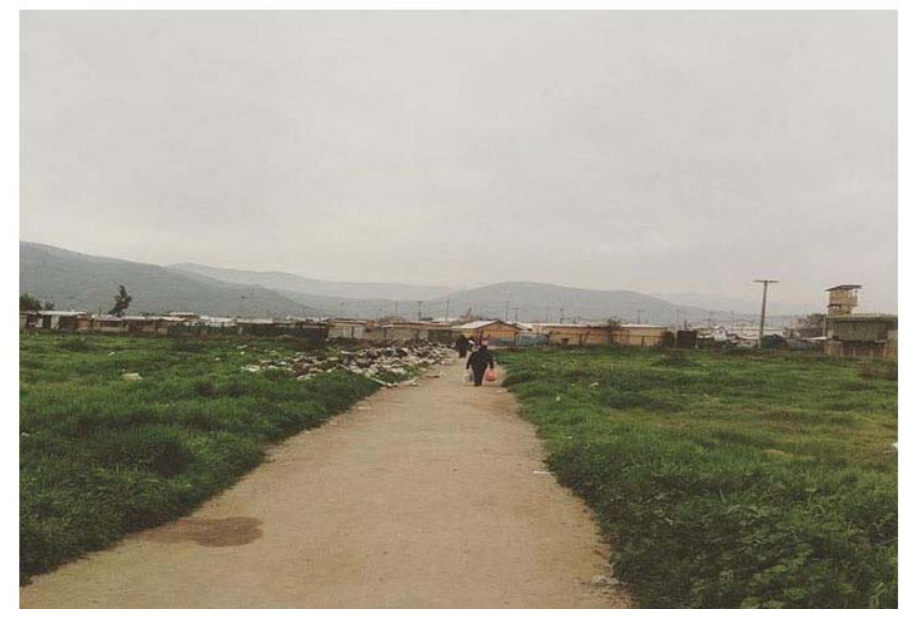

Figura 4: ingreso al campamento

Fuente: elaboración propia.

En cuanto a las ventajas de vivir en el campamento, los entrevistados mencionan que esto les permite principalmente no pagar arriendo. Cecilia, una migrante dominicana de unos 60 años, señala ante la pregunta por las ventajas de vivir en Nueva Vida "Sabes la plata que yo me he ahorrado de pagar en alquiler". Asimismo, también se considera una ventaja en cuanto a seguridad, ya que a pesar de que involucra un importante gasto de dinero, autoconstruir una casa en el campamento es visto como "tener algo seguro donde uno sabe que no le van a pedir la casa". En ese mismo sentido, también destaca la posibilidad de ir mejorando continuamente la vivienda con el dinero que se va ahorrando al no pagar arriendo. En cuanto a desventajas, los entrevistados suelen coincidir en un sentimiento de estigmatización por vivir en un campamento y ciertos problemas de seguridad, debido a la existencia, aunque minoritaria, de riñas y robos. Aun cuando se podría llegar a pensar que existe un sentimiento de exclusión territorial entre los residentes, debido a la lejanía geográfica que los separa del centro de la ciudad, la mayoría de ellos trabaja y hace su vida cotidiana en la misma comuna, cuestión por la cual la lejanía del centro de la ciudad no es vista como una desventaja. 
Ahora bien, el aspecto más relevante en relación a la construcción del hábitat residencial de las familias migrantes del campamento tiene que ver con la noción de los residentes de que las viviendas no están nunca terminadas. Dicho aspecto, se encuentra claramente expresado en las palabras de Robert, un haitiano de 38 años, que habita en Nueva Vida. Al preguntarle cuánto tiempo había demorado en construir su vivienda, éste señaló: “no, pero todavía no he terminado” “¿Qué le falta?”, pregunté, "Falta algo todavía; faltan muchas cositas", dijo de manera un tanto ambigua, como no teniendo claridad sobre aquello que pueda construir en el futuro. Luego, cerró su opinión afirmando:

"En cada momento usted coge algo [...] si no es por los materiales [faltantes], se puede hacer entre una semana. Pero puede compra algo --porque hay cosas que puedes comprar--, pero también hay cosas que usted mismo puede hacer. Todos los meses, cuando usted consigue algo [un material faltante], usted mete algo" (marzo 2018).

Visto así, la construcción de la vivienda se convierte en un proceso permanente e inacabado, que guarda relación con elementos que se consideran faltantes como arreglar el techo, poner piso de cerámica, cerrar las piezas, etc. Pero también con emergencias y contingencias como la llegada de un nuevo familiar, lo que implica agrandar una parte de la vivienda o acondicionar los espacios ya construidos.

Asimismo, existen una serie de criterios éticos y estéticos que condicionan el carácter inacabado de la vivienda. Aquí es donde hábitat y habitar se mezclan e intersectan, ya que como señala Giglia (2013) en el caso de los asentamientos informales, la misma construcción material del espacio va delineando los modos de habitar y las formas de apropiación espacial. En el campamento, esto se ve claramente expresado bajo la idea de "vivir bien" que mencionan los migrantes, en relación con sus vecinos chilenos, que según dicen "viven mal". Esto tiene que ver con una declaración ética, respecto a cómo se debe vivir, pero también con una serie de criterios estéticos que implican la mejora continua de la vivienda en el proceso mismo de su producción. Esto queda de manifiesto en una entrevista realizada a Alex, migrante dominicano de unos 35 años:

"Los chilenos viven como los animales [...]; los inmigrantes como los colombianos, los haitianos, los dominicanos, los peruanos, todos tienen su buena casita [pero los chilenos] son viciosos; yo voy a tener seis años aquí y me levanto a las seis de la mañana para ir a trabajar y ellos [los chilenos] no se van a levantar. Entonces, por eso uno puede comer bien, vivir bien. El animal come lo que encuentra, ellos hallan un pájaro y se lo comen y no les importa vivir en la cochinada. A uno [en cambio] le gusta vivir bien" (abril 2018). 
En el interior de la casa de Alex, quien vivía junto a su mujer e hijos, sobresalían las cerámicas con que había acondicionado su piso. Acentuaban también su desayunador estilo americano, un televisor de plasma y TV satelital, entre otros adornos y arreglos de la vivienda. Según comentó, construir su vivienda había implicado más de 3 meses y el gasto de más de 4 millones de pesos cifra que, aunque elevada, no era muy distinta de lo que otros migrantes aseguraban haber gastado para "vivir bien". Visto así, la noción de "vivir bien", se convierte en el elemento principal del habitar de los migrantes latinoamericanos que viven en el campamento. Esta noción, está relacionada con un imaginario respecto de la casa proyectada, pero también con el ejercicio rutinario de ir mejorando la vivienda mediante formas materiales que convierten el espacio en lugar vital. Esto queda más claro en la opinión de Alexis, migrante dominicano:

Pasa que nosotros tenemos otro tipo de costumbres. A nosotros nos gusta estar cómodos [...] nos gusta tener nuestro espacio ¿comprende? Por ejemplo, tener una radio, tener donde sentarse. A nosotros nos gusta tener nuestro espacio, vivir más tranquilo ¿comprende? (enero de 2018).

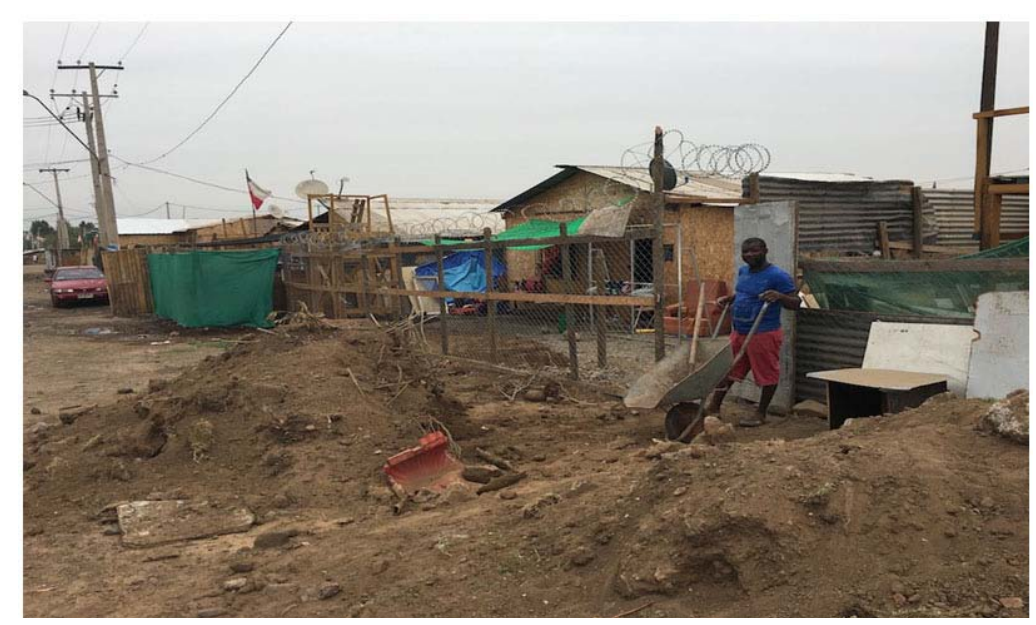

Figura 5: un migrante prepara materiales para su autoconstrucción Fuente: Elaboración de Miguel Pérez.

Visto de esta manera, no existe una actitud resignada respecto al lugar que han elegido para vivir, sino más bien un ejercicio permanente de apropiación del espacio construido, mediante rutinas de mejora y mantención de la vivienda, bajo criterios considerados propios de los migrantes que dan cabida a su lugar en la ciudad. A diferencia de los campamentos del pasado, donde el elemento comunitario resultaba ser uno de los aspectos más relevantes en relación con el habitar, en Nueva Vida, esto 
suele ser visto como un proyecto más bien de orden individual y familiar, de permanente distinción con respecto a los otros habitantes del campamento principalmente chilenos.

\section{Habitar las alturas: restricciones y subversiones}

Lo primero que salta a la vista son las enormes edificaciones. Las hay de 14, 16 y hasta más de 22 pisos. El sector conocido como Santa Isabel, entre las calles Alameda al Norte, Diez de Julio al sur, Vicuña Mackenna al oriente y Santa Rosa al poniente ha tenido un inusitado crecimiento poblacional asociado a la densificación en altura. El barrio se ha consolidado como uno de los de mayor crecimiento de la comuna de Santiago, principalmente por el desarrollo de proyectos inmobiliarios privados de grandes capitales financieros (IM Santiago, 2015). Estimaciones actuales hablan de un poco más de 60 mil habitantes solo en dicho sector. De ellos, al menos 10.000 son de origen migrante, siendo uno de los barrios con mayor número de extranjeros de origen latinoamericano en la capital (ATISBA, 2018).

A simple vista resulta difícil saber quién vive en el interior de estos edificios, pues la mayoría de ellos guarda férreas medidas de seguridad interna, con conserjerías y sistemas de televigilancia que dificultan la entrada a no residentes o visitantes no registrados. Sin embargo, es posible ir intuyéndolo a partir de la proliferación de varios comercios formales e informales, o "economías de la nostalgia" (Imilan e Iturra, 2014), que ofertan productos colombianos, venezolanos y peruanos como harina, pan, queso llanero, queso de mano, arepas, tequeños o chicha morada. En las alturas, una buena parte de los residentes son de origen latinoamericano y específicamente venezolano. Se puede ver desde abajo por algunas banderas venezolanas que flamean en las terrazas de los edificios.

La mayor parte de los migrantes que viven en estas edificaciones arriendan viviendas de una o dos habitaciones. Generalmente a inmobiliarias que toman el rol de arrendatarios mandatados por los dueños de los departamentos. En algunos casos viven parejas, pero también grupos de amigos o personas solas. 


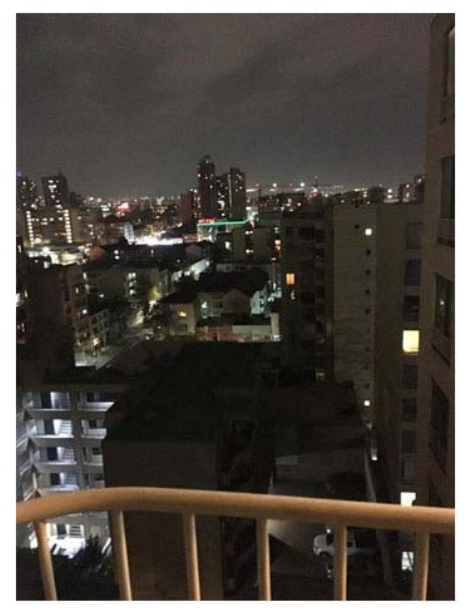

Figura 6: vista desde las alturas del edificio

Fuente: elaboración propia.

Es el caso de Adriana y su pareja Miguel, migrantes venezolanos de unos 30 años de edad, ingenieros de profesión, que viven hace un año en un departamento de calle Fray Camilo. El edificio tiene unos 2 años de inaugurado, según dicen por eso la mayoría de sus residentes son venezolanos, pues durante el último tiempo han ido llegando muchos a la capital. "Nos tendemos a agrupar" dice Adriana, ensayando explicaciones de por qué casi el $3 \%$ de los migrantes de dicho país viven en este sector del centro de Santiago. La mayoría trabaja en lugares céntricos y comunas aledañas como Providencia y Las Condes. Ello se debe a que una buena parte de los migrantes provenientes de Venezuela son profesionales altamente calificados: ingenieros, psicólogos, abogados, diseñadores, médicos, dentistas, aunque no muchos se desempeñan en estas áreas laborales.

Una buena parte de los edificios en que viven venezolanos como Adriana y Miguel comparten características comunes. Se trata de edificaciones de última renovación, que tienen entre 5 mil y 15 metros 2 construidos. Edificios de albañilería reforzada, hormigón armado y que se presentan como unidades repetitivas de gran altura. La mayor parte de los departamentos son unifamiliares, con 1, 2 y hasta 3 habitaciones, llegando a superficies de entre 40 y $75 \mathrm{~m} 2$. Además del arriendo, que va entre los 200.00o hasta los 450.000 en algunos casos, los residentes deben pagar gastos comunes que van entre los 70 mil y los 150 mil, destinados a la mantención del edificio, el pago de los conserjes y en algunos casos áreas verdes. Aunque una buena parte de los edificios no tienen muchas o estas son solo de orden ornamental. 
La vivienda de Adriana y Miguel está ubicada en el piso 14 del edificio. Para acceder a ella, se debe subir en uno de los dos ascensores dispuestos en la planta baja, a un costado de la conserjería. Al interior del n ${ }^{\circ} 409$, la vivienda se presenta como una de las típicas de departamento. Es de color blanco con tabiquería de madera que separa los espacios destinados para el uso abierto de la intimidad de la pieza. Al interior de la pieza, que está separada por una puerta de corredera hecha de vidrio y de madera, está la cama, dos veladores, un closet y el baño. Al igual que la mayoría de los departamentos del sector, gran parte de la casa se encuentra amoblada de antemano. La cocina está empotrada, tiene un desayunador americano, también incluido. Muebles de cocina y de baño.

Adriana y Miguel se apuran en decir que muy pocas cosas son suyas, el sofá cama que está en el living, la cama, una mesa de centro, un arrimo y el refrigerador. La mayoría de las cosas han ido siendo compradas recientemente. Cuentan que al principio solo tuvieron un colchón inflable y que fueron equipando la casa "de la pieza hacia afuera". Esto se repite en la mayoría de las entrevistas hasta ahora realizadas.

Cuando se les pregunta a los residentes por las ventajas y desventajas de vivir en estos edificios, rápidamente afloran cuestiones como la locación, la cercanía a servicios o el vivir cerca de familiares o amigos y que el departamento cuente con muebles y servicios básicos garantizados. Sin embargo, precipitadamente surge también, en el caso de las desventajas, problemas asociados a la serie de restricciones que presenta la vida en departamentos. Que "no se puede hacer nada, ni pegar un clavo", dice Marta, una venezolana de 35 años de edad que vive hace más de dos años en un departamento de la calle Lira, junto a su hermano y dos amigos. Que cada vez que hace una fiesta debe estar atenta al citófono porque no tardan en llamar los conserjes con reclamos de los vecinos. La vida en los edificios del barrio Santa Isabel se encuentra muy reglamentada. Son muy pocas cosas las que se pueden modificar, Marta señala, por ejemplo, que el reglamento del edificio prohíbe usar la terraza como bodega. Así también, comenta que cuando arrendó el departamento, junto a su hermano y dos amigos, la agente inmobiliaria le recordó que solo podía vivir una persona o una pareja por pieza, cuestión que se complica a la hora de dividir los costos del departamento, que, entre 4 personas, recién se vuelve más o menos económico.

A diferencia del campamento, donde todo está más o menos por hacer y se asume que las viviendas no están terminadas. En los departamentos del barrio Santa Isabel, existe la idea de que es poco lo que se puede modificar no siendo propietario. Aun así, surgen una serie de subversiones y modificaciones que van modificando materialmente el espacio. Tal es el caso de Marco, migrante venezolano que vive con su pareja en un edificio de la calle Lira. Marco colgó el televisor de plasma que tiene en el living al techo, "dice [el reglamento] que nada de hoyos en las paredes", remata risueño". Dando cuenta de que existen vacíos susceptibles de reinterpretarse a la luz de vivir de manera más cómoda y de acuerdo a las necesidades familiares. 


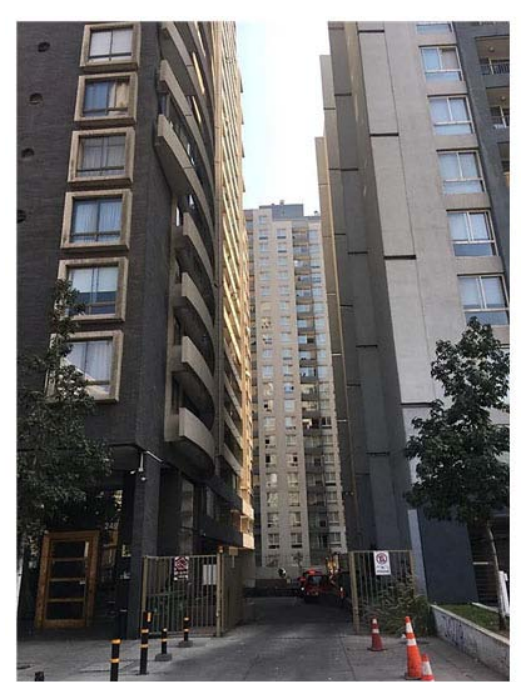

Figura 7: fachada del edificio de Marta

Fuente: elaboración propia.

La mayoría de los residentes, sin embargo, tiende a cumplir con las normas, para evitar multas y problemas. En ese sentido, el carácter de arrendatarios de los residentes, sumado a las prohibiciones explicitas en los reglamentos dificulta bastante la posibilidad de modificar y amoldar el hábitat a las necesidades de los residentes.

El equipamiento de las viviendas suele ser bastante semejante y remite a cuestiones funcionales. Una buena parte de ellas tienen un sillón cama, que se utiliza para dar alojamiento a familiares o amigos que llegan desde el país de origen y a la vez para descansar en la sala de estar. Sin embargo, en algunos casos como el de Marta, la casa se adorna con ciertos objetos que recuerdan al país de origen. Ella tiene colgado un cuatro venezolano en una de las paredes de la vivienda, que, cuenta, se lo trajo su madre de Venezuela cuando vino de visita, pues a ella le gusta mucho tocar música. A diferencia de sus guitarras, que están guardadas en su pieza, el cuatro ${ }^{4}$ luce colgado al lado del televisor, en pleno living.

Más allá de esto, las apropiaciones espaciales de la residencia se producen sobre todo a nivel afectivo. Adriana y Miguel, señalan que sienten que el departamento que habitan es importante pues ha sido su primer lugar para vivir juntos. Igualmente, Marta, dice que su casa es una suerte de residencial, a la cual le tiene mucho cariño pues por ahí han pasado familiares y amigos. Su departamento, al ser más grande que el resto de los del sector, es también espacio de encuentro para amigos y familiares, que, según agrega son más de 20 desde que su tío vino a Chile hace 3 años. En todos

4. Instrumento musical de cuatro cuerdas de origen venezolano. 
los casos, los residentes de departamentos aspiran a salir de ahí una vez que se modifique su situación familiar o cambien las condiciones de arriendo, "sabemos que estamos de paso, pero mientras estamos acá nos gusta sentir que esto es un hogar, hacer un hogar" añade Marta.

\section{Reflexiones finales}

Con el paso de los años, los migrantes latinoamericanos se han ido asentando en una multiplicidad de áreas sobre la ciudad. A diferencia de décadas pasadas, donde los migrantes peruanos ocuparon mayormente zonas pauperizadas del pericentro urbano, en la actualidad y con la mayor afluencia de migrantes de varios países de América Latina y el Caribe han surgido nuevas formas de hábitat residencial como la vida en campamentos y en nuevas edificaciones de altura. En este artículo hemos querido repasar la influencia del hábitat, en cuanto integración de hechos físicos y materiales en el espacio, en relación a la capacidad de los sujetos migrantes de apropiarse de dichos espacios. Como se ha dicho, en ambos casos es posible apreciar formas de apropiación espacial. En el hábitat de" madera", en el campamento Nueva Vida, hemos visto como conforme se procede a la autoconstrucción de la vivienda se van desarrollando nociones sobre la casa proyectada y el ejercicio rutinario de la mantención y mejora del espacio para convertirlo en un lugar que integra las expectativas e imaginarios de sus residentes. En el hábitat de hormigón, hemos visto como a través de pequeños actos de subversión, sentimientos y simbolismos asociados a la vivienda se va cargando el espacio de sentido vital e integración del sello propio de sus usurarios.

En tal sentido, esta investigación sobre hábitat residencial migrante y formas de habitar, viene a mostrar que la vivienda y el barrio, también son ejes donde se actualizan, superponen y modifican los órdenes tradicionales del hábitat, permitiendo (nuevos) usos, apropiaciones y afectos.

Finalmente decir que este trabajo es apenas un esbozo de una agenda de investigación mayor que puede, sin duda, abrirse a las diferentes maneras en que la migración latinoamericana está modificando el espacio urbano y residencial. Se espera, en el futuro, poder arribar a mejores y más sólidas conclusiones.

\section{Referencias}

Álvarez, Eduardo y María Verónica Blanco (2013). Componer, habitar, subjetivar. Bifurcaciones. Revista de Estudios Culturales Urbanos,15: 1-12. Recuperado de http:// www.bifurcaciones.cl/2013/12/componer-habitar-subjetivar/.

ATISBA (2018). El mapa de la inmigración en Santiago. Localización espacial de inmigrantes Censo 2017. Recuperado de http://www.atisba.cl/wp-content/ uploads/2018/o7/Reporte-Atisba-Monitor_Mapa-Inmigraci\%C3\%B3n-en-Santiago.pdf. 
Camacho, Mario (2001). Diccionario de Arquitectura y Urbanismo. México: Editorial Trillas.

Contreras, Yasna, Veera Ala-Louko, y Gricel Labbé (2015). Acceso exclusionario y racista a la vivienda formal e informal en las áreas centrales de Santiago e Iquique. Polis, 14(42): 53-78.

Clichevsky, Nora (200o). Informalidad y Segregación urbana en América Latina. Una Aproximación. CEPAL, Serie 28 Medio Ambiente y Desarrollo.

Curahua, Delia (2013). Integración social y protección de los derechos humanos de los migrantes. En Migraciones: Conferencia internacional sobre migraciones y Derechos Humanos. Santiago: Editorial Aún Creemos en los sueños.

De la Puente, Patricio, Patricia Muñoz, y Emilio Torres (1989). Un marco conceptual para la definición de hábitat residencial urbano. Santiago: Editorial Universidad de Chile, Facultad de Ciencias Sociales.

Di Virgilio, María, María Arqueros y Tomás Guevara (2010). Veinte años no es nada. Procesos de regularización de villas y asentamientos informales en la Región Metropolitana de Buenos Aires. Scripta Nova, XVX (331): 1-19.

Garcés, Alejandro (2012). Localizaciones para una espacialidad: territorios de la migración peruana en Santiago de Chile. Chungará - Revista de Antropología Chile$n a, 44(1): 163-175$.

Giglia, Ángela (2013). El habitar y la cultura. México D.F: Siglo XXI Editores.

Guber, Rosana (2001). La etnografía, método, campo y reflexividad. Bogotá: Norma.

Imilan, Walter (2014). Restaurantes peruanos en Santiago de Chile: construcción de un paisaje de la migración. Revista de Estudios Sociales, 35(48): 15-28.

Imilán, Walter y Luis Iturra (2014). Narrativa visual del paisaje migrante. Aproximaciones desde la etnografía y el video como herramientas de exploración urbana. Revista 180, 18 (34): 10-15.

Instituto Nacional de Estadísticas. (2019). Estimación de personas extranjeras residentes en Chile. INE-DEM. Recuperado de https://www.ine.cl/docs/default-source/demogr\% $\mathrm{C}_{3} \%$ A1ficas-y-vitales/estimaciones-personas-extranjeras/sintesis-estimacion-de-personas-extranjeras-residentes-en-chile.pdf?sfvrsn=ce195bd2_14.

Jirón, Paola y Pablo Mansilla (2014). Las consecuencias del urbanismo fragmentador en la vida cotidiana de habitantes de la ciudad de Santiago de Chile. EURE, 40(121): 5-28.

Lefebvre, Henri (1975). De lo rural a lo urbano. Barcelona: Península.

López-Morales, Ernesto, Pablo Flores \& Hernán Orozco (2018). Inmigrantes en campamentos en Chile: ¿mecanismo de integración o efecto de exclusión?. Revista INVI, 33(94): 159-185. 
Luque, José Carlos (2004). Transnacionalismo y enclave territorial étnico en la configuración de la ciudadanía de los inmigrantes peruanos en Santiago de Chile. Revista Enfoques, 3, 81-102.

Negro, Virginia (2016). Tácticas del habitar. La producción social del hábitat como estrategia cotidiana para la construcción de una nueva ciudadanía urbana. Contested Cities, 507, 1-11.

Margarit, Daisy y Karina Bijit (2014). Barrios y población inmigrante: el caso de la comuna de Santiago. INVI, 81(29): 19-77.

Márquez, Francisca (2014). Inmigrantes en territorios de frontera: La ciudad de los otros. Santiago de Chile. EURE, 4O(120): 49-72.

Skewes, Juan (2005). De invasor a deudor: el éxodo desde los campamentos a las viviendas sociales en Chile. En A. Rodríguez \& A. Sugranyes (editores) Los con techo. Un desafío para la política de vivienda social. Santiago: Ediciones Sur.

Stefoni, Carolina (2015). Reconfiguraciones identitarias a partir de habitar el espacio público. El caso de los migrantes esquineros en la ciudad de Santiago, Chile. Chungará, Revista de antropología chilena, 47(4): 669-678.

Tapia, Ricardo, Carlos Lange y Jorge Larenas (2009). Factores de deterioro del hábitat residencial y vulnerabilidad social en la conformación de barrios precarios: breve revisión de algunos programas de barrios en Chile y en la Región. Santiago de Chile: Universidad de Chile, Programa Domeyko, Cuaderno de Trabajo Volumen $\mathrm{N}^{\circ}{ }_{1}$.

\section{Sobre el autor}

Cristóbal Palma es Antropólogo Universidad Alberto Hurtado, Magister (c) en Sociología. Universidad Alberto Hurtado. Correo Electrónico: cristobal.spr@gmail. com. ${ }^{(D)}$ htps://orcid.org/0000-0002-4590-3145 


\title{
CUHSO
}

Fundada en 1984, la revista CUHSO es una de las publicaciones periódicas más antiguas en ciencias sociales y humanidades del sur de Chile. Con una periodicidad semestral, recibe todo el año trabajos inéditos de las distintas disciplinas de las ciencias sociales y las humanidades especializadas en el estudio y comprensión de la diversidad sociocultural, especialmente de las sociedades latinoamericanas y sus tensiones producto de la herencia colonial, la modernidad y la globalización. En este sentido, la revista valora tanto el rigor como la pluralidad teórica, epistemológica y metodológica de los trabajos.

\author{
EDITOR \\ Matthias Gloël \\ COORDINADORA EDITORIAL \\ Claudia Campos Letelier \\ CorReCTOR DE ESTILO Y DISEÑADOR \\ Ediciones Silsag \\ Traductor, CORRECTOR LENGUA INGLESA \\ Aurora Sambolin Santiago \\ SITIO WEB \\ cuhso.uct.cl \\ E-MAIL \\ cuhso@uct.cl
}

LICENCIA DE ESTE ARTÍCULO

Creative Commons Atribución Compartir Igual 4.0 Internacional 